\title{
In no certain terms
}

\author{
The court's inconsistent \\ approach to the role of sexual \\ grooming when sentencing in \\ cases of the sexual abuse of \\ children under 16
}

\author{
Nicole van Zyl* \\ Nicole.vz42@gmail.com \\ http://dx.doi.org/10.17159/2413-3108/2018/i65a4473
}

This article considers whether evidence of sexual grooming influences decisions by South African courts when passing sentence on offenders who have been found guilty of sexual assault or rape of children. By analysing judicial decisions, the article considers three themes - the lack of violence, the apparent consent of a child under 12, and the appropriateness of correctional supervision. The article concludes that evidence of grooming should play a role in sentencing decisions, as it forms part of the nature of the crime that the court is required to consider.

The concept of sexual grooming is new in South African law, with a fledgling jurisprudence and an even younger statutory provision. This article examines six cases in which a child under the age of 16 was raped ${ }^{1}$ or sexually assaulted ${ }^{2}$ by an adult, and where there was evidence of sexual grooming that facilitated the completion of the offence. The article examines whether the presence of sexual grooming is considered by the court when passing sentence, and if so, in what way it influences the decision. From the analysis of case law, it is argued that in order to arrive at an appropriate sentence, the court must consider the broad factual circumstances - which include the grooming process - when

\footnotetext{
* Nicole van Zyl is a Sonke Gender Justice Fellow at the University of California, Los Angeles, in the David J Epstein Public Interest Litigation and Policy LLM programme. She completed her LLB at the University of Cape Town in 2016, and an LLM in Criminology, Law and Society at the same institution in 2017.
}

discussing the nature of the crime and the interests of society, balanced against the interests of the offender.

This analysis is independent of the stand-alone offence of sexual grooming in section 18 of the Criminal Law (Sexual Offences and Related Matters) Amendment Act (SORMA) of 2007. Section 18 criminalises specific conduct that may form a part of the grooming process and can be considered unlawful, even if it never culminates in a sexual offence against the child. The cases examined in this article may include some of the conduct criminalised by section 18, but also encompass the broader understanding of grooming adopted in case law. The concept of sexual grooming is an important one when considering whether the court should accept the apparent consent of a child. There is an innate power imbalance between an adult and a child that should demand heightened 
scrutiny. At its core, evidence of grooming has the ability to negate a defence of consent when establishing criminal liability. ${ }^{3}$ In addition, it continues to play a role at the sentencing stage owing to the many considerations at play when deciding on an appropriate sentence. This article draws on a broader definition of grooming than the one included in the legislation, to reflect some of the psychological features discussed in the case law.

The article briefly describes grooming and its different roles in the law, and then proceeds to describe the general law on sentencing in which evidence of grooming may play a role. This role is then examined in various judicial decisions, in an analysis that considers three specific themes. First, it canvasses decisions that have highlighted the lack of violence in an offence, and then it considers two cases that were appealed as a result of judicial reliance on consent of a child under 12 when deciding on sentence. It considers two cases where the courts looked into whether correctional supervision would be an appropriate sentence, and the role that evidence of grooming played in the outcome. This article concludes that evidence of grooming is an important consideration in the sentencing process for persons convicted of rape or sexual assault of children, based on the outcomes of the cases examined.

\section{Sexual grooming}

Sexual grooming is understood in the literature as a process where an adult subjects a child to psychological manipulation and violation of their developing sexuality. ${ }^{4} \mathrm{~A}$ perpetrator will make use of their adult authority or economic resources to draw a child into a relationship that is for the benefit of the perpetrator's sexual desires. ${ }^{5}$ The child may adopt responsibility for the violation they suffer because they feel complicit, because they fear their abuser, or because they have become emotionally dependent on the abuser. ${ }^{6}$ The process of grooming is one that does not require the use of force precisely because of the child's complicity or fear. ${ }^{7}$ This broad understanding of sexual grooming in the law is discussed in the minority decision of $S v \operatorname{Marx}(2005)^{8}$ and the decision in $S$ v Muller. ${ }^{9}$

\section{Grooming has been recognised as a gateway} to sexual abuse, and, as a result, the legislature saw fit to include it as a stand-alone crime in section 18 of SORMA. ${ }^{10}$ Classification of this new offence aims to protect children from incidents of sexual abuse, as the abuser may be prosecuted under this section even before a sexual violation has occurred. Section 18 also defines specific conduct that falls under the definition of grooming, such as showing pornography to a child in order to encourage or instruct that child to perform a sexual act, ${ }^{11}$ or arranging to meet a child with the intention that the meeting will result in a sexual act. ${ }^{12}$

The approach of the courts has been much more broad and flexible in establishing the presence of sexual grooming than the definition contained in the legislation. $S v$ Muller defined grooming as 'a psychological process used by the paedophile to access his victim'. ${ }^{13}$ This broad definition allows the court to take into account all of the offender's conduct surrounding the sexual abuse. It is able to do so because punishment is not being imposed for a separate offence of grooming, but, instead, evidence of grooming supports the prosecutor's case of alleged rape or sexual assault. In practice, then, a set of facts may satisfy the elements of the crime of grooming under section 18 of the Act, as well as supporting a broader understanding of grooming based on the psychological features of the process, and how this process created the context in which the sexual offence could occur.

\section{Sentencing in grooming cases}

The cases considered in this article all deal with a successful conviction of an accused for rape 
or sexual assault of a complainant who is younger than 16. The article does not focus on the role that grooming played in securing the convictions, but rather on how it affected the sentencing of the offender. Such a discussion warrants some background on the sentencing framework, before turning to the discussion on grooming in these cases.

At the heart of any sentencing decision is an application of the Zinn triad, as set into law by the decision of $S v$ Zinn where Justice of Appeal Rumpff held that 'what has to be considered is the triad consisting of the crime, the offender and the interests of society'. ${ }^{14}$ As will be shown later in this article, evidence of grooming is taken into account when establishing the nature of the crime, which in turn affects sentencing. For example, whether an offence is deemed to be sexual assault or rape has important implications at sentence. When sentencing an offender convicted of sexual assault (section 5 of SORMA), the court needs only to consider the common law on sentence. Grooming that leads to rape (under section 3 of SORMA) will, however, trigger the imposition of a mandatory minimum sentence under section 51 of the Criminal Law Amendment Act 105 of 1997 (CLAA), read with the Criminal Law (Sentencing) Amendment Act 38 of 2007 . As a result, sentencing an offender who is convicted of rape is more complex.

Rape of a child under 16 years old falls under part 1 of schedule 2 of the CLAA. The court must sentence a person convicted of such a crime to a life sentence. The court's discretion to deviate from the statutory minimum sentence is limited to cases where 'substantial and compelling circumstances' exist that justify the imposition of a lesser sentence. ${ }^{15}$ In addition, section 51(aA) prohibits the court from considering 'the apparent lack of physical injury to the complainant' as a substantial and compelling circumstance that justifies such a deviation. ${ }^{16}$ This becomes relevant, as the cases examined lacked any physical injury considered to be significant or lasting. However, in practice the apparent lack of injury still formed part of the list of factors that the court considered in mitigation of sentence in some decisions.

The application of the CLAA is guided by the decision in $S$ v Malgas, which intended to provide clarity on when a court could deviate from the prescribed minimum sentence. ${ }^{17}$ Justice of Appeal Marais's judgment requires that the prescribed minimum sentence ordinarily be imposed, but that if the case calls for a departure from the sentence, the court should do so guided by notions of justice and proportionality. ${ }^{18}$ Marais notes that 'the greater sense of unease a court feels about the imposition of a sentence, the greater its anxiety will be that it may be perpetrating an injustice'. ${ }^{19}$

In practice, addressing this 'unease' varies from case to case, as courts attempt to deal with questions of (dis)proportionality in sentencing. It does mean, however, that the judicial officer retains substantial discretion in the imposition of sentence. ${ }^{20}$

Adding an additional charge of sexual grooming cannot increase the amount of time an offender spends in prison. However, evidence of sexual grooming (as a separate offence or merely as part of the fact pattern of the sexual offence) can still impact severity of sentence when considering the Zinn triad. S v Steyn illustrates the impact on sentence when an offender has committed an offence under section 18 of SORMA, in addition to having committed a sexual offence. ${ }^{21}$ Steyn deals with the persistent sexual abuse of the offender's stepson. The accused would masturbate his stepson, or himself in front of his stepson, in order to encourage him to do the same. This conduct, which spanned two years, resulted in a charge of sexual assault. The accused began his abuse after his stepson came to him to discuss his sexual education in school. The accused used this natural adolescent enquiry to discuss 
masturbation, with the result that he was also charged with sexual grooming. The judge described the offender's conduct as using 'the guise of a parental interest in SR's development to encourage SR into sexual acts with him at a time when he was young and impressionable, and dependent on [him]'. ${ }^{22}$

This case highlights an important principle in sentencing, which holds that where there are multiple offences, the offender's sentences should run concurrently if the 'evidence shows that the relevant offences are "inextricably linked in terms of locality, time, protagonists and, importantly, the fact that they were committed with one common intent"'. ${ }^{23}$ Under this principle, offenders such as Steyn, who commit sexual assault or rape through a process of grooming, and are also charged with the separate section 18 offence, must have sentences that run concurrently. The judge in Steyn held that 'the appellant's sexual grooming of SR was committed with an intent to ... reduce SR's unwillingness to the appellant committing acts of sexual assault against SR'. ${ }^{24}$ The sentences for the various convictions were therefore ordered to run concurrently.

\section{Case analysis}

This article considers how judges have considered features of the grooming process when passing sentence on an offender. As noted above, in cases where the grooming results in rape, the court must make its decision in keeping with legislation imposing a mandatory minimum sentence. Even in cases of sexual assault that do not trigger a mandatory minimum sentence, the court's reasoning often follows similar considerations as set out in the sentencing framework. A court may therefore take features of the grooming process into account when deciding to either reduce or impose a harsher sentence.

The consequences of grooming in facilitating abuse vary from case to case, and there is, as a result, no clear guidance on how grooming should be considered when sentencing an offender. This discussion analyses the cases of offences facilitated through grooming along three themes. The first theme considers decisions that rely on a lack of violence in mitigating sentence. The second theme discusses two cases where the court relies on the apparent consent of a child under the age of 12 to justify reducing the sentence for a rape conviction. The third theme examines cases where correctional supervision was deemed appropriate for an offender in a grooming-related case. All three themes show the variability of sentence outcomes, which highlights the need for proper recognition of how grooming forms an integral part of the sexual offence that is committed. By failing to make this link, prosecutors and judges make decisions that perpetuate harmful perceptions about children and sexual abuse.

\section{Lack of violence}

$S v$ Muller concerned the rape of a 14-year-old girl (on two occasions) by her stepfather. The accused was found guilty on two counts of rape. The age of the complainant, and the fact that the offence had occurred more than once, triggered the application of the minimum sentence of life imprisonment as prescribed by section 51(1), ${ }^{25}$ which Justice Satchwell ultimately imposed on the accused. ${ }^{26}$ The judge was asked to consider whether a number of factors met the standard for 'substantial and compelling circumstances' that warranted a deviation from the mandatory minimum sentence. As part of these arguments, the defence raised the lack of violence and absence of bodily injury that characterised the rape. Satchwell held that

it is difficult to comprehend how this could be relevant or mitigating in circumstances where no violence or threat of violence was needed by the rapist to achieve his deeds. ${ }^{27}$ 
This judgment succeeded in excluding a core feature of the grooming process - the fact that an offender does not have to resort to the use of force because of the child's complicity or fear - from constituting a substantial and compelling circumstance to deviate from a sentence of life imprisonment.

The decision in $S v A S^{28}$ follows a different approach to that taken in Muller. The offender indecently assaulted his goddaughter, and he was prosecuted under the common law because, at the time of the incident, SORMA was not yet in place. Because of the restrictive common law definition of rape, and the fact that his case involved oral penetration of the complainant with his penis, the offender was charged with indecent assault. (Had the incident occurred after the commencement of the new law, the accused would have been guilty of rape.) Evaluating the accused's conduct, Justice Lekale writes that 'the abuse would have, most probably, culminated in rape in the common law sense as the child gradually got accustomed to it and the number and value of gifts increased'. ${ }^{29}$ This judgment shows an appreciation of the ways in which the grooming process operates. However, the judge later also includes 'the fact that the complainant in this matter did not sustain any physical injuries'30 as a justification for reducing the court a quo's sentence.

These two cases show how the same core feature of the grooming process can be used in contradictory ways by different judicial officers. Grooming as a psychological process secures the compliance of the child involved, which means that violence is not necessary for the offender to achieve their ends. Muller found that the lack of violence was insufficient grounds to deviate from the prescribed minimum, while in the case of $A S$ it was considered a mitigating factor in favour of the offender.

The law now prohibits lack of violence from constituting a substantial or compelling circumstance under section 51(3) (aA) of the CLAA. This means that judges cannot rely on a lack of violence in mitigation of sentence. This is especially relevant in the context of grooming, where the nature of the crime necessarily excludes violence. A consideration of the contextual factors that lead to the offence, with due appreciation of the mechanisms through which the grooming process occurs, can help prevent such a decision.

\section{Consent of a child under 12}

Two matters travelled to the appeal court because of a specific factual consideration used by the judge in deciding on an appropriate sentence. In both cases, the court was faced with a complainant under the age of 12 , who is, by definition, unable to consent to sex under section 57(1) of the SORMA. ${ }^{31}$ In both cases, however, the judge used the apparent consent or compliant behaviour of the child as a substantial and compelling factor that justified the imposition of a lesser sentence. Both cases occurred in the same court's jurisdiction, and the Director of Public Prosecutions, Gauteng appealed both sentences as incorrect in law.

The first matter, MJM v $S,{ }^{32}$ concerned a case where the accused had what was described as an ongoing sexual relationship with an 11-yearold girl, to which she seemingly acquiesced. Justice of Appeal Mushasha notes that 'counsel [for the state] argued strongly on the doctrine of grooming', ${ }^{33}$ which the court accepted, but did not explore. When considering arguments against the imposition of a life sentence the judge writes that 'it seems to me that the only aggravating factor in this case is the age of the complainant'. ${ }^{34}$ The list of mitigating factors he relies on to reduce the sentence includes the 'cooperation of the complainant'35 in giving the accused access to her home, and that

the complainant proceeded of her own accord to appellant's home ... It is remarkable that complainant's visit took 
place despite the fact that she was already

previously raped by the appellant. ${ }^{36}$

The process of grooming will often result in a compliant victim, because the child is emotionally manipulated to participate through guilt or loyalty. This compliance from a child is what makes ongoing sexual abuse by an adult possible. By including them as mitigating factors in this matter, the judge used core features of the grooming process as a reason to deviate from the statutory minimum sentence of life in prison to 20 years' imprisonment.

The decision in MJM was appealed in Director Public Prosecutions, Gauteng v Mphaphama. ${ }^{37}$ The state sought to appeal the sentence under section 16(1)(b), read with section 17(3) of the Superior Courts Act 10 of 2013, on the grounds that the High Court had erred in law when including the consent of the complainant as a consideration in imposing sentence. The state based its argument on the fact that section 57(1) of SORMA establishes that a child under the age of 12 is unable to consent. Although the court ruled that it did not have the necessary jurisdiction ${ }^{38}$ to hear the appeal, Justice of Appeal Willis made sure to comment that 'while the approach of the High Court in this matter is to be strongly deprecated, our hands are tied'. ${ }^{39}$ Although the outcome was not successful, this decision has the positive effect of censuring the approach taken in Mushasha's original decision in case law.

The Gauteng Director of Public Prosecutions was offered another opportunity to challenge the use of the compliance of a child under the age of 12 as a substantial and compelling circumstance in S V MG. ${ }^{40}$ This case concerned an appeal of conviction and sentence of multiple charges against the accused, who was the stepfather of the 11-year-old complainant, and who was accused of raping her, as well as producing pornographic images of her. The appeal was based on issues of evidence collection and presentation before the court. The judge found that the accused had inserted his penis into the mouth of the complainant, and photographed the incident. ${ }^{41}$

The accused was found guilty of rape, and when considering the appropriate sentence, Justice Preller noted that 'there is a strong suspicion that the victim was not an unwilling participant in the events'. ${ }^{42}$ This impression was based partly on the complainant's oral testimony: she did not express disgust or hurt at the actions of the appellant, and although a threat was used to ensure her compliance ${ }^{43}$ this did not take place before every incident. These findings, coupled with the expression on her face in the photographs where she has the appellant's penis in her mouth, were relied on to suggest that she was not unwilling or forced. Preller concludes on the complainant's evidence as to the nature of the crime:

I am fully aware that she was at the time only 10 years old and that the absence or otherwise of consent is irrelevant as an element of the commission of the offence. It must, however, be an important factor in considering an appropriate sentence.

This consideration, along with the offender's youthfulness and his experience of abuse as a child, led the court to justify a deviation and impose a 10-year sentence for rape. The case was taken on appeal, ${ }^{44}$ where the Supreme Court of Appeal (SCA) held (per Justice of Appeal Petse) that the court did have the power to overturn the sentence imposed, ${ }^{45}$ due to the incorrect legal basis of the High Court decision:

In this case the High Court imputed consent to the complainant. It did so despite the clear and unequivocal provisions of s 57(1) of the Sexual Offences Act ... In doing so, the High Court committed an error of law. ${ }^{46}$ 
This allowed the SCA to refer the matter back to the High Court to be sentenced afresh. In doing so the court noted that

the respondent gratuitously violated that complainant's right to dignity, privacy and physical integrity in a most humiliating and demeaning manner. Accordingly, on the facts of this case one must ... keep uppermost in the mind, with a measure of abhorrence, the respondent's unfatherly conduct in sexually molesting

his stepdaughter. ${ }^{47}$

Following this SCA decision, the High Court takes a very different approach to sentencing in Grobler v S. ${ }^{48}$ Justice Fisher's judgment is more victim-centred and focuses on the experience of the complainant, although there was not much evidence of her actual experience before the court. Fisher writes:

[W]hilst she should have been nurtured and guided at this crucial stage of her young life, she was predated upon by the appellant who was opportunistic, in taking advantages of the absences of her mother from the home. ${ }^{49}$

The lack of evidence as to the impact on the victim (owing to a failure to admit the victim impact statement to the court) sets a useful standard for sentencing:

[E]ven if it were assumed that the complainant would have been found in such a report to have experienced little or no trauma as a result of the offences, this would not serve to ameliorate their seriousness for the purposes of the enquiry as to whether substantial and compelling circumstances exist to depart from the prescribed sentence. ${ }^{50}$

Fisher does not find any reasons to justify a departure from the mandatory minimum sentence as a result of a more detailed consideration of the nature of the offence and the victim's interests. ${ }^{51}$

The original High Court decisions in these two cases show how an outcome of the grooming process - the apparent consent or compliance of a child - was relied on in mitigation of sentence. The SCA decision in MG should put an end to this reasoning in cases involving victims under the age of 12 , as it clearly sets out that any reliance on the consent of a child under the age of 12 in mitigation of sentence is an error in law because of their statutory inability to give consent. Evidence of grooming remains relevant to a decision of sentence, as it speaks to the nature of the offence, as demonstrated by the decision in Grobler, where the court draws on the complex features of grooming within the home in establishing the serious nature of the crime.

\section{Correctional supervision and grooming}

Enslin $v$ State ${ }^{52}$ and $S$ v $A R^{53}$ provide interesting counterpoints on the question of whether correctional supervision is an appropriate sentence in cases where a rape or sexual assault is facilitated through grooming.

In Enslin, the offender had been convicted in the regional court of rape of his 17-year-old stepdaughter, as well as of various acts of sexual assault, which began when she was 14. He was also convicted of sexual grooming. The regional court imposed a sentence of eight years for the rape, which the offender appealed before the High Court. Although the various convictions suggest that the complainant was groomed over a number of years during her adolescence, the judge accepted without much comment the argument in mitigation that

the complainant showed no resistance. The complainant did not sustain injuries during the commission of the rape and ... the appellant penetrated the complainant's vagina with his finger. ${ }^{54}$ 
The court does make the connection between the psychological abuse over the years with the complainant's eventual compliance. Had argument been led that the compliance was a product of the cycle of abuse, the judge may have viewed the evidence of grooming differently. Instead, the judge makes the general comment that

sexual assault on children is devastating and leaves an indelible mark in the psychological upbringing of a child; it is even more so when such offences are committed within the household by a father who is naturally entrusted with the protection of his children. ${ }^{55}$

Here, although there was evidence of grooming, it did not feature in Justice of Appeal Magardie's discussion of the crime (which was limited to the submissions made by counsel for the offender). Recognition of the pattern of abuse suffered by the complainant would have made the outcome more palatable, but the decision is instead focused on the offender. Magardie's decision to sentence the perpetrator to correctional supervision is explained as follows:

The sentencing courts cannot apply the one-size fits all approach when sentencing offenders. Ordinarily, a distinction should be made between those offenders who ought to be removed from society and those who, although deserving of punishment, should not. With appropriate conditions, correctional supervision is undoubtedly an appropriate and severe punishment, even for persons convicted for serious offences. ${ }^{56}$

Magardie decides to replace the regional court's sentence of eight years' imprisonment with one of correctional supervision.

Justice Le Grange and Justice of Appeal Weinkove adopted a different approach in $S v$ $A R$, which concerned an accused who created child pornography with his stepdaughter, and with other children known to him. None of the charges involved violent acts, although the circumstances in which the photos were taken resulted in conviction for sexual assault. The offender was given an eight-year sentence (wholly suspended) by the regional court. The state appealed this sentence as too lenient. The judges in this matter held that

a non-custodial sentence would, in our view, unduly focus on the rehabilitation of the respondent and would lessen the retribution and prevention elements of sentence, to the extent that it would bring the administration of justice into disrepute..$^{57}$

The judges reached this conclusion through a more detailed canvassing of the offences in question. In discussing the images taken of his stepdaughter, the judges address her apparent compliance:

The filming and taking of nude pictures of LC happened over a period of years and multiple videos were made. In our view it is incongruous to suggest that LC was a 'willing participant' [suggested by the magistrate] in the true sense of the words. ${ }^{58}$

This decision shows an understanding of the process under which the eventual compliance was obtained. The judges go on to say:

Common sense dictates that the respondent must have over a period of time created a false sense of security and trust with LC. The respondent's behaviour in this regard can hardly be described as less serious. In fact the opposite is more accurate. It was this false sense of trust, if not grooming, which allowed LC to participate and not speak out. ${ }^{59}$

By highlighting the process under which the offender was able to secure compliance, the 
judges succeed in increasing the focus on the nature of the crime within the triad, rather than the disproportionate focus on the offender of the initial judgment. This shift in focus results in the judges imposing an eight-year sentence of direct imprisonment.

These two cases illustrate how the inclusion of a consideration of grooming when sentencing an offender may change the sentence quite dramatically. Both cases involved grooming over a number of years, with the result that the complainants were compliant to the whims of the offender at the time of discovery. Both men were stepfathers, who were responsible for the complainants and trusted to provide safety and care. This position gave them a special kind of power and influence over the developing adolescents. Both men were respectable members of society, gainfully employed and breadwinners for their families. Both men showed remorse, and willingness to be reformed. This became the core feature in the Enslin judgment but not in $A R$, where the nature of the offence (which included the grooming process) was foregrounded in the decision. This disparity suggests that evidence of grooming can impact the severity of sentence, depending on the way it is used to negate the existence of consent. The approach taken by the court in $A R$ is preferable, as it balances the factors in the Zinn triad effectively while affording the victims of sexual abuse through grooming the understanding they deserve.

\section{Conclusion}

Sexual grooming is a complex psychological process by which a child becomes compliant to the sexual advances of an older, often trusted person. This process may result in psychological trauma before sexual abuse occurs. This article has considered how evidence of sexual grooming plays a role in the sentencing of offenders who have been convicted of rape or sexual assault of a child. Each child's experience of being groomed is different, and it is critically important to scrutinise how the courts have used the facts of being groomed, and how they have sentenced offenders who have made use of this manipulation.

Overall, the case law discussed above has shown that there is no clear-cut outcome when evidence of sexual grooming is led in sentencing proceedings. Taking into account the factors in the Zinn triad, a judicial officer may focus on features of the process in a way that results in aggravation or mitigation of sentence. The absence of violence that characterises a violation does not produce a consistent outcome, as shown by the difference in decisions in Muller and AS. The SCA decision of $M G$ prevents sentencing courts taking the compliant behaviour of children under 12 into account in mitigation of sentence in the future, but it does not guarantee the same for children over 12. Finally, the contradiction in outcome between Enslin and $A R$ reveals how a focus on evidence of grooming, when considering the nature of the crime, might impact outcomes. If the psychological process of grooming the child is not taken into account, more weight may be placed on the offender's characteristics, as it did in Enslin. AR, on the other hand, shows that the nature of the offence must be properly balanced against the offender's considerations in order to achieve an appropriate and sensitive sentence. This latter approach is preferable in sexual offence cases that are facilitated through grooming. The absence of violence in a rape or sexual assault matter should not constitute a factor that allows for mitigation of sentence. Apparent consent after psychological manipulation should also not allow for leniency. While sentencing is a process that depends intimately on the facts of the case before the court, evidence of grooming should be something that produces similar outcomes in punishment. 


\section{Acknowledgements}

My deepest thanks to Bronwyn Pithey for lending her experience and guidance on the various drafts of this article.

To comment on this article visit

http://www.issafrica.org/sacq.php

\section{Notes}

1 Criminal Law (Sexual Offences and Related Matters) Amendment Act of 2007 (Act 32 of 2007) (SORMA), section 3.

2 Ibid., section 5.

$3 \quad \mathrm{~N}$ van Zyl, Sexual grooming of young girls: promise and limits of the law, Agenda, 31:2, 2017, 44.

4 S Ost, Getting to grips with sexual grooming? The new offence under the Sexual Offences Act 2003, Social and Legal Studies, 26, 2004, 147-159.

5 A McAlinden, 'Setting 'em up': personal, familial and institutional grooming in the sexual abuse of children, Social and Legal Studies, 15, 2006, note 3.

6 A Salter, Transforming trauma: a guide to understanding and treating adult survivors of child sexual abuse, Newbury Park: Sage Publications, 1995, 74.

7 McAlinden, 'Setting 'em up', 347.

8 S v Marx (2005) 4 All SA 267 (SCA).

9 S v Muller (2007) JOL 19407 (W).

10 Section 18 of SORMA lists types of conduct that are criminalised as the crime of either sexual grooming or promoting sexual grooming.

11 SORMA, section 19(2)(a)(ii).

12 Ibid., section 18(2)(c).

13 S v Muller, 35.

14 S v Zinn 1969 (2) SA 537 (A), P540G.

15 SORMA, section $51(3)(a)$.

16 This section was inserted by the Criminal Law (Sentencing) Amendment Act of 2007 (Act 38 of 2007).

17 S v Malgas 2001 (2) SA 1222 (SCA).

18 S Terblanche, Mandatory and minimum sentences: considering s 51 of the Criminal Law Amendment Act 1997, Acta Juridica, 2003:1, January 2003, 213.

$19 S$ S Malgas, 22.

20 KS Baehr, Mandatory minimums making minimal difference: ten years of sentencing sex offenders in South Africa, Yale Journal of Law and Feminism, 20:1, 2008, 227.

21 S v Steyn 2014 JDR 2271 (GJ).

22 Ibid., 12.

23 Ibid., 68, quoting S v Mokela 2012 (1) SACR 431 (SCA).

24 Ibid., 80.

25 SORMA, section 51(1) requires the imposition of a life sentence based on factors contained in part I of schedule 2 . Schedule 2 includes rape in circumstances where the victim was raped more than once. It also includes rape when the victim is under the age of 16 .
26 Although this case was decided before the inclusion of section 51(3)(aA), which prohibits the court from considering lack of violence as a factor, it uses a similar approach.

27 S v Muller, 9, 84.

$28 S v$ AS 2012 JDR 2554 (FB).

29 Ibid., 36.

30 Ibid., 36.

31 SORMA, section 57(1): 'Notwithstanding anything to the contrary in any law contained, a male or female child under the age of 12 years is incapable of consenting to a sexual act.'

32 MJMv S (2014) JO 32265 (GP).

33 Ibid., 15.

34 Ibid., 25.

35 Ibid., 20.

36 Ibid., 20.

37 Director Public Prosecutions, Gauteng v Mphaphama 2016 (1) SACR 495 (SCA)

38 Judge of Appeal (JA) Willis held that the court did not have the necessary jurisdiction to hear an appeal, as section 1 of the Superior Courts Act excludes jurisdiction on any matter regulated by the Criminal Procedure Act 51 of 1977 (CPA). The court then finds the matter to be excluded based on section 316B of the Criminal Procedure Act, which, based on the interpretation in Director of Public Prosecutions $v$ Olivier 2006(1) SACR 380 (SCA), only allows appeals against sentence by a High Court acting as the court a quo. Here the High Court had acted as a court of appeal. Because of the provision in section $316 \mathrm{~B}$ of the CPA and section 1 of the Superior Courts Act, Willis held that the court did not have the jurisdiction to hear the appeal.

39 Director Public Prosecutions, Gauteng v Mphaphama, 12.

40 S v MG 2015 JDR 0131 (GP).

41 Other allegations of vaginal and anal penetration were not proved beyond a reasonable doubt because the complainant described the accused as having touched her there, but not having put his penis inside of her.

42 SVMG, 15.

43 In her evidence the complainant stated that she participated in these activities with the appellant because he told her there would be trouble if she did not do as he told her.

44 Director of Public Prosecutions, Gauteng v MG 2017 (2) SACR 132 (SCA).

45 On appeal the SCA held that the court did have the power to overturn the sentence imposed by the High Court based on circumstances near identical to those in Mphaphama. JA Petse decided that the question raised by the Director of Public Prosecutions (DPP) was to be decided under section 311 of the CPA, which allows the DPP to appeal a decision in favour of the accused if it is regarding a question of law. Petse distinguished the current matter from that in Mphaphama. This was grounded in the finding that a judicial discretion exercised based on an incorrect legal basis was a question of law, which drew the matter within the ambit of section 311 of the CPA. See Director of Public Prosecutions, Gauteng v MG, 35.

46 Director of Public Prosecutions, Gauteng v MG, 28.

47 Ibid., 35. 
49 Ibid., 40.

50 Ibid., 46.

51 Ibid., 40. Fischer paints a detailed picture that highlights many elements of grooming in his consideration of the nature of the crime. 'In this case, what should have been the home and sanctuary for the child was turned into a place where she found herself subject to the worst threats imaginable, and this from a man who purported to be her guardian and protector. She was subjected, not only to fear and mental anguish over a protracted period of time, but also to degradation and humiliation of a type which struck at the very core of her developing self. Whilst she should have been nurtured and guided at this crucial stage of her young life, she was predated upon by the appellant who was opportunistic, in taking advantage of the absences of her mother from the home. She was deprived of the comfort and protection of her mother and other adults by being intimidated by the appellant into keeping his confidences. This is not the type of sexual abuse which allows escape for the victim from the perpetrator. It is domestic in nature. The victim must reside with him at close quarters and feel his constant gaze upon her and his presence around her. She must enter into the pretence of normality in the face of extreme aberration. It is apparent that the sexual abuse of the child in this case was not isolated nor was there an end in sight for her. Had the appellant not been caught, the indications are that he would have continued his abuse of her. The pornographic material made by him and his preserving thereof can only be seen in a context of his wishing to extend and enhance, for his purposes, whatever personal gratification he derived from his violations of the child. He has shown no remorse or regret and neither has he made any move to take any responsibility for his crimes. His conduct shows a large measure of planning and deviousness.'

52 Enslin v State 2016 PHC 1090 (GP).

$53 S v A R 2017$ (2) SACR 402 (WCC).

54 S v Enslin, 9

55 Ibid., 12.

56 Ibid., 18.

$57 S \vee A R, 49$.

58 Ibid., 38.

59 Ibid., 38. 